\title{
Stochastic System Dynamics Modelling for climate change water scarcity assessment on a reservoir in the Italian Alps
}

\author{
Terzi Stefano ${ }^{1,2,3}$, Sušnik Janez ${ }^{4}$, Schneiderbauer Stefan ${ }^{1,3,5}$, Torresan Silvia ${ }^{2,6}$, Critto Andrea ${ }^{2,6}$
}

${ }^{1}$ Eurac Research, Institute for Earth Observation, Viale Druso 1, 39100, Bolzano, Italy

$5 \quad 2$ Department of Environmental Sciences, Informatics and Statistics, University Ca' Foscari Venice, Via Torino 155, I-30172 Venezia-Mestre, Venice, Italy

${ }^{3}$ United Nations University Institute for Environment and Human Security (UNU-EHS), Platz der Vereinten Nationen 1, 53113 Bonn, Germany

${ }^{4}$ Land and Water Management Department, IHE Delft Institute for Water Education, 2601DA, Delft, Netherlands

$10{ }^{5}$ University of the Free State, Department of Geography, Bloemfontein, South Africa

${ }^{6}$ Fondazione Centro-Euro Mediterraneo sui Cambiamenti Climatici (CMCC), via Augusto Imperatore 16, I-73100, Lecce, Italy

Correspondence to: Stefano Terzi (stefano.terzi@eurac.edu)

\section{Abstract.}

Water management in mountain regions is facing multiple pressures due to climate change and anthropogenic activities. This is particularly relevant for mountain areas where water abundance in the past allowed for many anthropogenic activities, exposing them to future water scarcity. To better understand the processes involved in water scarcity impact, an innovative stochastic System Dynamics Modelling (SDM) explores water stored and turbined in the S.Giustina reservoir (Province of

20 Trento, Italy). The integration of outputs from climate change simulations as well as from a hydrological model and statistical models into the SDM is a quick and effective tool to simulate past and future water availability and demand conditions. Shortterm RCP4.5 simulations depict conditions of highest volume and outflow reductions starting in spring (-16.1\% and $-44.7 \%$ in May compared to the baseline). Long-term RCP8.5 simulations suggest conditions of volume and outflow reductions starting in summer and lasting until the end of the year. The number of events with stored water below the 30th and above the 80th quantiles suggest a general reduction both in terms of low and high volumes. These results call for the need to adapt to acute short-term water availability reductions in spring and summer while preparing for hydroelectric production reductions due to the chronic long-term trends affecting autumn and mid-winter. This study provides results and methodological insights for potential SDM upscaling across strategic mountain socio-economic sectors (e.g., hydropower, agriculture and tourism) to expand water scarcity assessments and prepare for future multi-risk conditions and impacts. 


\section{Introduction}

Mountains serve as "water towers" providing freshwater to a large portion of the global population (IPCC, 2014b, 2018; Rull, 2014; United Nations, 2012; Viviroli et al., 2007). Climate change affects mountain environments more rapidly than many other places, with impacts on glaciers, snow precipitation, water flows and on the overall supply of water (Viviroli et al., 2011; Barnett et al., 2005). These impacts call for the need to shift water management towards more sustainable and adaptive practices. Adaptation delays and unpreparedness to water availability changes can spread consequences across multiple systems, from natural ecosystems to anthropogenic activities relying on water (van den Heuvel et al., 2020; Mehran et al., 2017a; Fuhrer et al., 2014; Xu et al., 2009).

The European Alps are among those mountain regions where water abundance in the past allowed for the development of

40 activities with intensive water use such as large hydropower plants and irrigated agriculture, making them susceptible to future impacts regarding reduced water availability (Majone et al., 2016; Beniston and Stoffel, 2014; Permanent Secretariat of the Alpine Convention, 2013). That is, in many Alpine regions the socio-ecological systems are unprepared for water scarcity and hence the impacts of water shortage can be more severe (Di Baldassarre et al., 2018).

Previous studies have assessed the hydrological processes involved in mountain environments, looking at the overall

45 hydrological dynamics (Bellin et al., 2016) or specifically assessing topics such as glacier melt and runoff (Huss and Hock, 2018; Farinotti et al., 2012), and snowpack runoff (Etter et al., 2017; Wever et al., 2017). However, the interplay connecting natural processes and socio-economic activities, sometimes known as sociohydrology (Di Baldassarre et al., 2015; Sivapalan et al., 2012) calls for further research. There is a need to implement methodologies with the ability to unravel this complexity, dynamically describing such interplays and system behaviours to find which adaptation strategies across economic sectors can

50 effectively tackle climate-related water issues.

System Dynamics Modelling (SDM) is a methodology used to improve the understanding of complex systems and their dynamic interactions. Previous applications of SDM often rely on deterministic assumptions (Mereu et al., 2016; Sahin and Mohamed, 2014; Sušnik et al., 2013), while statistical analysis of trends and interactions are crucial under uncertain climate change and risk assessments (Terzi et al., 2019). These conditions call for probabilistic system dynamics assessments to better understand the dependencies between anthropogenic and environmental processes, which can lead to multiple cascading and interrelated impacts, water disputes and crises. Statistical methods combined with SDM present an innovative and powerful opportunity to overcome the current limitations involved in deterministic assessments.

This study explores the S.Giustina reservoir in the Noce catchment, Province of Trento, Italy, considering current conditions and future climate change effects leading to critical states of volume of water stored and turbined outflows for

60 hydropower production. By doing so, the aim is to test and demonstrate a stochastic SDM as a quick and effective tool to assess climate change impact on water scarcity in one of the main reservoirs in the north east of the Italian Alps supporting its adaptation planning. 
In section 1, the concepts behind SDM and the innovation of its applications are described. Section 2 focuses on the case study characteristics and the recently arisen water management challenges. Section 3 describes the methodology, data and scenario used for the simulations. Section 4 focuses on the results of SDM application for both the baseline and future projections. Section 5 involves the discussion of the results and its limitations. Future developments and applications are described in section 6 .

\section{System dynamics modelling}

SDM is an approach used in the field of complex system behaviour. It makes use of four main modelling elements connected to each other: (i) stocks (system state variables) - 'accumulating' material (e.g. water in a reservoir); (ii) flows (variable's rate of change) -moving material into and out of stocks (e.g. river inflows and outflows), (iii) converters parameters influencing the flow rates (e.g. evaporation rates modulated by temperature) and (iv) connectors - transferring causal connections and/or feedback loops - (e.g. linking temperature variations to the evaporation rate) (Sterman et al., 2000). The combination of these elements is applied to represent temporal changes in system elements accounting for endogenous and exogenous influences on system behaviour. This concept encourages a system thinking approach, splitting large systems into sub-systems and progressively increasing their interactions and complexity (Gohari et al., 2017; Mereu et al., 2016). SDMs can combine different metrics and indices, improving models by adding social, economic and environmental sectors (Terzi et al., 2019). Moreover, it can implement a graphical interface, supporting the visualization of interactions and feedback loops during participatory approaches.

While SDM was developed to improve industrial business processes (Forrester, 1971), it has been successfully applied to model human and natural resources interactions (Meadows et al., 2018). Moreover, SDM applications span a wide range of problems, from climate change risk assessments (Duran-Encalada et al., 2017; Gohari et al., 2017; Masia et al., 2018), water management issues (Davies and Simonovic, 2011; Gohari et al., 2017), disasters studies (Menk et al., 2020; Simonovic, 2001, 2015), water-energy-food nexus studies (Sušnik et al., 2018; Davies and Simonovic, 2008) and applications fostering participatory modelling (Malard et al., 2017; Stave, 2010). It is therefore the ideal tool to study complex interactions and dynamic behaviour in a wide variety of complex systems (Ford, 2010).

However, SDM also shows some limitations, such as (i) the limited spatial representation since it works with lumped regions, although recent research has coupled SDM to GIS to account for spatially explicit system dynamics (Neuwirth et al., 2015; Xu et al., 2016); (ii) the reduced accuracy in comparison with dedicated physically based models; (iii) the fact that applications usually account for deterministic approaches, although recently, stochastic analysis have been used for probabilistic SDM output (Sušnik et al., 2018); (iv) the ease of creating very complex what-if scenarios that can be difficult to validate, but which are useful to explore systems behaviour under potential futures, giving general ideas of likely system trajectories. 
This study focuses on a novel refinement of SDM applications implementing a stochastic assessment of variable interactions for robust validation of uncertainties and trends, particularly useful in the field of risk assessment. Conceptual diagrams of system variable interactions were elaborated using the Stella software (https://www.iseesystems.com/) while statistical correlations and dependencies were analysed in R (Duggan, 2016; R Core Development Team, 2013). This innovative combination contributes to improving SDM analysis accounting for the uncertainty and variability associated with past and future water flow data.

\section{Case study}

The Noce river (Province of Trento, Italy) in the south-eastern part of the Alps (Figure 1) is a tributary of the Adige river, the second longest river in Italy. The Noce river basin is a typical Alpine basin characterized by intensive anthropogenic activities including hydropower plants in the upper part of the catchment relying on glacier melting, to intensive apple orchards shaping the landscape of valley bottoms, and tourism flows with high water demands during winter and summer time for sport activities (i.e. skiing, hiking and kayaking).

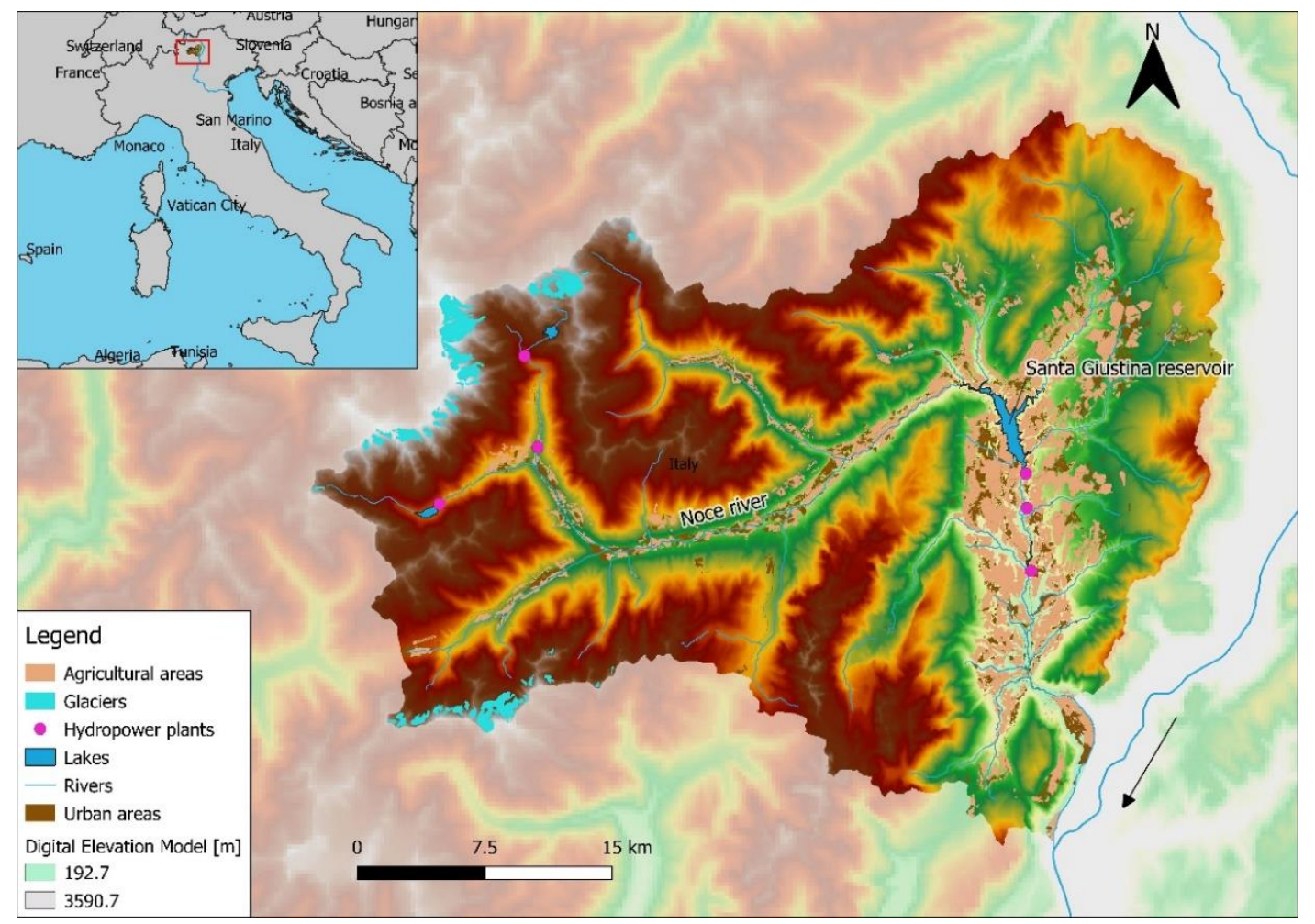

Figure 1 - Noce river basin and main characteristics. The black arrow specifies the Adige river flow direction.

Water has always been considered abundant in most regions in the Alp region, and only recent events of water scarcity in 2015 and 2017 raised wider concerns about water quantity and quality (Stephan et al., 2021; Chiogna et al., 2018; Hanel et al., 
110 2018; Laaha et al., 2017). Temperature increase, loss of glacier mass volume and decreased snow precipitation during winter are among the causes of reduced summer discharge and water availability both in mountain areas and downstream. At the same time, numerous activities have flourished such as increasing hydropower plants, agricultural production, urbanisation, industrial activities and more intense tourism all demanding large water amounts to satisfy their needs. Tensions for water allocation have recently arisen asking for a fair use of the resource among different actors. In particular, associations and civil

115 society groups (e.g. local association for the Noce river safeguard: https://nocecomitato.wordpress.com/) were established at provincial level showing their concerns about ecological impacts of further exploitation (i.e. hydropower plants). Within this context, climate change effects at regional level have already been recognized acting on the current water balance and triggering multiple impacts on a wide range of economic activities relying on water use (La Jeunesse et al., 2016; Zebisch et al., 2018).

In the Noce river basin, the S. Giustina reservoir provides a large buffer for water resources regulation. The reservoir has a storage capacity of $172 \mathrm{Mm}^{3}$ (equal to a maximum net available volume of $152.4 \mathrm{Mm}^{3}$ ), the largest reservoir volume within the Trentino-Alto Adige region. It was built in the 1940's and 1950's for hydropower purposes. Nowadays, the reservoir has a multipurpose function, producing a large amount of energy (i.e. installed power of $108 \mathrm{MW}$ ), and regulating water flow for downstream users and providing water for irrigation. Moreover, the local water use plan (Provincia Autonoma di Trento, 2006) established a monthly minimum ecological flow threshold ranging from 2.625 to $3.675 \mathrm{~m}^{3} \mathrm{~s}^{-1}$ to sustain fluvial ecosystems, raising concerns among the different stakeholders on the possible economic impacts of "unused" water releases.

Within this context, a better understanding of the complex interactions in the S.Giustina water management represents a crucial step to prepare to future impacts of climate change on freshwater resources affecting different sectors. The representation of connections and interactions using SDM can help to depict the S.Giustina reservoir dynamics and its

130 responses to future pressures, including climate change and anthropogenic factors. Such information could inform water operators, local and provincial authorities fostering a discussion on the implementation of climate change adaptation strategies in line with the Water Framework Directive (European Parliament \& Council, 2000).

\section{Material and methods}

The methodological approach here presented is composed of 5 sequential phases, from (1) the development of a causal

135 loop diagram, (2) the set-up of a System Dynamics Model (SDM), (3) the analysis of variables' interactions, (4) model calibration and validation on historical observations and finally (5) the integration of future projections. Each of the stages is described in this section. 


\subsection{Causal loop diagram}

A first system conceptualization aims to identify the variables and their interactions involved in S.Giustina dam management and climate effects on water availability. Following the terminology developed by IPCC (2014a) within the $5^{\text {th }}$ Assessment Report, a causal loop diagram (CLD; Ford, 2010) was developed considering the S.Giustina water reservoir operations (Figure 2). The CLD was compared to the IPCC risk components to graphically represent the comprehension of variables and their interactions leading to critical states. Climate hazard was considered as future regime variations of temperature and precipitation with respect to the baseline. Vulnerability variables refer to physical-environmental definitions only, while exposed elements considered the S.Giustina dam reservoir and its operations potentially involved in risk conditions related to variations in the water turbined and the water volume stored in time.

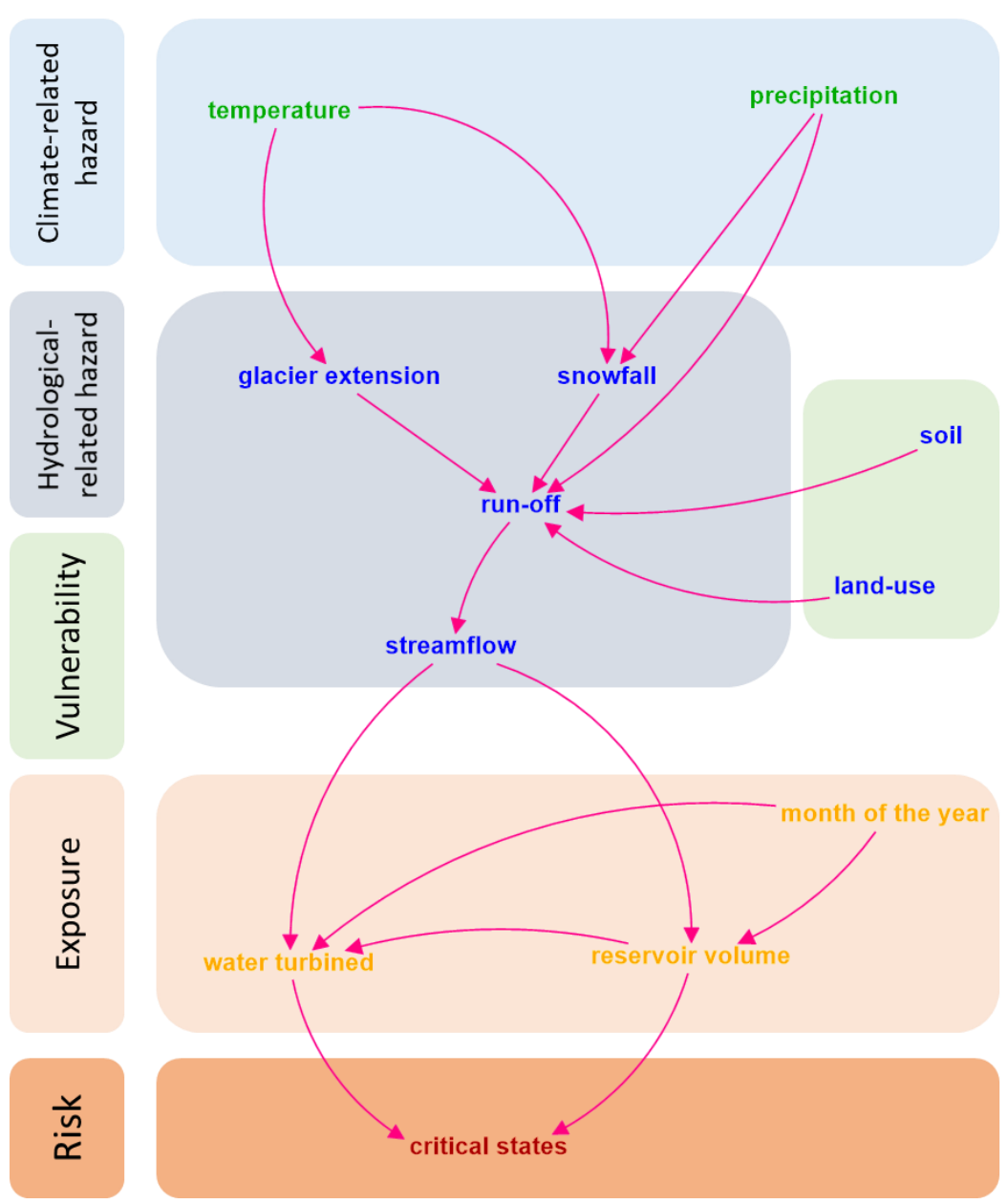

Figure 2 - Causal loop diagram used to describe the risk variables and their interactions leading to critical states of S.Giustina reservoir operations. Climate variables are in green font, blue font for hydrological-related components, yellow font variables are 


\subsection{System dynamics modelling set-up and input data}

Starting from the CLD conceptualization, an SDM was developed integrating multiple sources of data (e.g. observations, modelled values and climate projections) and connecting climate change effects with reservoir operations. By doing so, it was possible to explore impacts on water stored and turbined in S.Giustina reservoir from climate and water streamflow changes within the SDM. Figure 3 shows the different components which were used and incorporated in the SDM for the assessment of S.Giustina critical states.

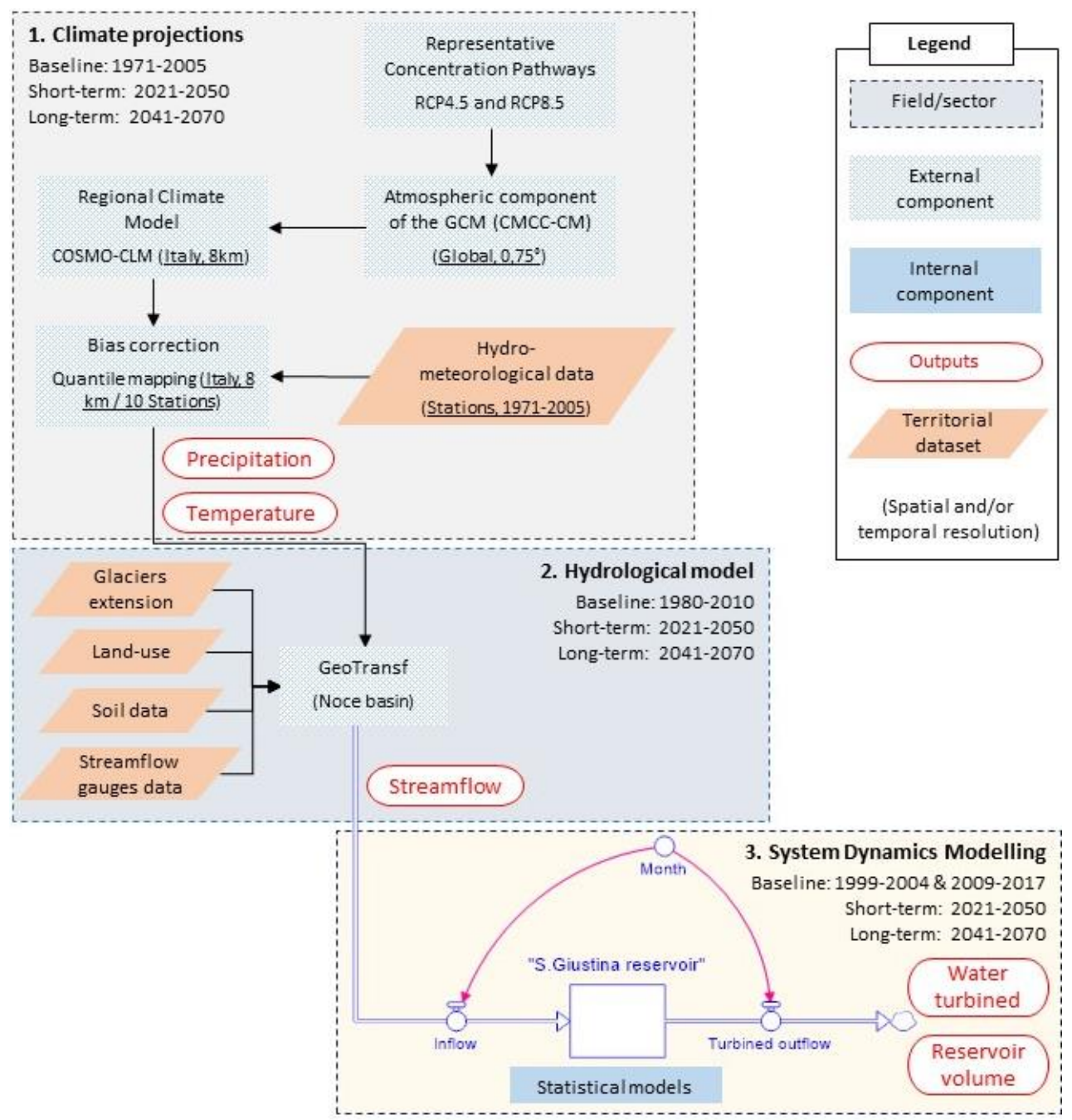

Figure 3 - Modelling approach to quantify the impacts of climate change (box 1) on water streamflow (box 2), water stored and turbined for hydropower production (box 3). Sources: adapted from Pham et al., 2018; Ronco et al., 2017.

The climate projections in box 1 (Figure 3) provide information stemming from global climate models downscaled to regional level, and bias corrected with local weather stations to better simulate climate local conditions. In this study, the regional climate model COSMO-CLM (Climate Limited-area Modelling) was selected for its spatial resolution of $0.0715^{\circ} \times$ 
$0.0715^{\circ}(\approx 8 \mathrm{~km} \times 8 \mathrm{~km})$ allowing local level climate impact assessment (Rockel and Geyer, 2008). Such model information was developed by the CLM community and provided by Euro-Mediterranean Centre on Climate Change (CMCC) for the application to the Noce catchment (Bucchignani et al., 2016). Temperature and precipitation data were used as input to the physically-based model "GeoTransf" (Bellin et al., 2016) together with topographical information to replicate streamflow conditions of the Noce river (box 2 in Figure 3). These blocks were provided as an output from the OrientGate project (http://www.orientgateproject.org/) and used as an input to the SDM (box 3 in Figure 3). GeoTransf was calibrated and validated on past water flow data in the case study area considering a baseline time range from 1980 to 2010 (Bellin et al., 2016; Majone et al., 2016). GeoTransf provides a description of the hydrological dynamics within the Noce alpine river catchment, assessing variations in water contributions coming from climate change effects in terms of temperature, soil moisture, glaciers, snow and rainfall. Moreover, GeoTransf was applied with COSMO-CLM precipitation and temperature scenarios from 2021 until 2070 over the Noce catchment to assess future conditions of river discharge at local level for the Representative Concentration Pathways (RCPs) 4.5 and 8.5 (Bucchignani et al., 2016). These applications of GeoTransf were used as input to the stochastic SDM to focus on the S.Giustina reservoir operations and simulate future conditions accounting for climate change impacts and human management (box 3 in Figure 3). The baseline simulation period was bound to available data. In the case of climate data from COSMO-CLM, precipitation and temperature data were available from 1975 to 2005. These data were used to consider the Noce catchment climatology and to compare the baseline with future conditions of precipitation and temperature for the two RCPs. For water inflows and outflows, and water volume stored in the reservoir, the baseline period ranges from 1999 to 2004 and from 2009 to 2017 (Table 1).

The SDM in Figure 3 was built from GeoTransf outputs aiming to integrate human dynamics in a probabilistic manner, assessing the management of the reservoir and its vulnerability to changing environmental conditions. The SDM covers two variables exposed to critical conditions: one focusing on the water volume stored within the reservoir (Volume) and the other representing the water outflow diverted to the turbines for hydropower production (Outflow).

185 Table 1 - Selected variables within the statistical SDM in box 3 for the S.Giustina reservoir.

\begin{tabular}{llll}
\hline Data type & Variable name & Time range & Source \\
\hline $\begin{array}{l}\text { Simulated inflows to S.Giustina } \\
{\left[\mathrm{m}^{3} / \mathrm{s}\right]}\end{array}$ & Geotransf_inflows & $1981-2010$ & GeoTransf hydrological model \\
\hline $\begin{array}{l}\text { S.Giustina outflows for } \\
\text { hydropower use }\left[\mathrm{m}^{3} / \mathrm{s}\right]\end{array}$ & Outflow & $1981-2017$ & Province of Trento - Agency for \\
W.Giustina volume $\left[\mathrm{Mm}^{3}\right]$ & Volume & $\begin{array}{l}1999-2004 \\
2009-2017\end{array}$ & \\
\hline
\end{tabular}




\subsection{Variables' interaction analysis}

This analysis aims to quantitatively describe the existence and type of interactions among the systems variables. Statistical regressions were carried out considering both different input variables (e.g. inflow, hydroelectric energy market price, temperature, precipitation and water outflows from an upstream dam reservoir) and statistical models, including linear regression and more flexible generalized additive models (Table 2). For the simulations of water stored and turbined outflows, a linear mixed effects model was selected (models \#3 and \#4, with adjusted R2 of 0.68 and 0.74 and RMSE of $12.12 \mathrm{Mm}^{3}$ and $12.35 \mathrm{Mm}^{3} \mathrm{~s}^{-1}$, Table 2) because of its ability to account for monthly variations and its lower proneness to overfit calibration data (i.e. compared to flexible non-linear models). A monthly time step was chosen to better describe the intra-seasonal dynamics of water availability, which can be useful for water demand assessments, and for long-term dynamics representation for climate impact assessment (e.g. seasonal changes). Further information on input variables, their tested combinations for model selection and link to the open code is reported in the Supplementary material.

Table 2 - Tested model and their performance indicators (adjusted $\mathbf{R}^{2}$ and the root mean square error (RMSE). The formula syntaxes follow that from the R packages "Ime4" (for the linear mixed effects model) and "mgcv" (for the generalized additive model). Full list of tested models and their features is reported in the Supplementary material

\begin{tabular}{|c|c|c|c|c|}
\hline Model types & $\#$ & Formulas & Adjusted $\mathbf{R}^{2}$ & RMSE \\
\hline \multirow{2}{*}{$\begin{array}{l}\text { Multi-linear } \\
\text { model }\end{array}$} & 1. & $\operatorname{lm}($ Volume $\sim \operatorname{lag}($ Geotransf_inflows $)+\operatorname{lag}($ Outflow $))$ & 0.36 & 18.20 \\
\hline & 2. & $\operatorname{lm}($ Outflow $\sim$ Geotransf_inflows + lag(Volume $))$ & 0.72 & 13.09 \\
\hline \multirow{2}{*}{$\begin{array}{l}\text { Linear mixed } \\
\text { effect model }\end{array}$} & 3. & lmer (Volume $\sim$ Geotransf_inflows $+(1 \mid$ month $))$ & 0.68 & 12.12 \\
\hline & 4. & lmer $($ Outflow $\sim$ Geotransf_inflows $+\operatorname{lag}($ Volume $)+(1 \mid$ month $))$ & 0.74 & 12.35 \\
\hline \multirow{2}{*}{$\begin{array}{l}\text { Generalized } \\
\text { additive model }\end{array}$} & 5. & $\operatorname{gam}($ Volume $\sim \mathrm{s}(\operatorname{lag}($ Geotransf_inflows $))+\mathrm{s}(\operatorname{lag}($ Outflow $))$ & 0.44 & 22.13 \\
\hline & 6. & gam $($ Outflow $\sim \mathrm{s}($ Geotransf_inflows $)+\mathrm{s}(\operatorname{lag}($ Volume $)+\mathrm{s}(\mathrm{mo}))$ & 0.72 & 16.86 \\
\hline \multirow{2}{*}{$\begin{array}{l}\text { Generalized } \\
\text { additive mixed } \\
\text { model }\end{array}$} & 7. & $\begin{array}{l}\text { gam }(\text { Volume } \sim \mathrm{s}(\operatorname{lag}(\text { Geotransf_inflows }))+\mathrm{s}(\operatorname{lag}(\text { Outflow }))+ \\
\mathrm{s}(\mathrm{mo}, \mathrm{bs}=" \mathrm{re} "))\end{array}$ & 0.50 & 20.88 \\
\hline & 8. & $\begin{array}{l}\text { gam }(\text { Outflow } \sim \mathrm{s}(\text { Geotransf_inflows })+\mathrm{s}(\text { lag }(\text { Volume }))+\mathrm{s}(\mathrm{mo}, \\
\mathrm{bs}=" \mathrm{re} "))\end{array}$ & 0.72 & 16.86 \\
\hline
\end{tabular}

\subsubsection{Reservoir volume}

The simulation of reservoir water volumes and outflows for hydropower production was developed combining Stella conceptualization with statistical analysis using R. The lme4 package in R (Bates et al., 2015) was applied to perform a linear 
mixed effect analysis of the relationship between water volumes stored in the reservoir (i.e. V) and the water flowing into the reservoir (i.e. $\left.Q_{\text {in }}\right)$ in Eq. (1):

$$
\mathrm{V}(\mathrm{t})=f\left(Q_{\text {in }}(t), \text { month }\right)
$$

where, as the fixed effect the water flowing into the reservoir (i.e. $Q_{i n}$ ) was considered, accounting for the linear relation with the water volume stored. As a random effect, the month of the year was selected (month) for its grouping effect on the recurrent water volume variations on a monthly scale. By doing so, it was possible to describe the reservoir water volume and future changes combining the physically-based model outputs with statistical analysis aiming to explore the reservoir volume vulnerability to changing conditions.

\subsubsection{Hydropower outflows}

A statistical analysis was carried out to simulate the turbined outflows from the S.Giustina reservoir for hydropower production. Similarly to equation 1, a linear mixed effect analysis was selected, simulating the water diverted to the turbines as a function of water flowing into the reservoir, the volume state in the previous month $(\mathrm{V}(\mathrm{t}-1))$ and the month of the year 215 in Eq. (2).

$Q_{\text {out }}(t)=f\left(Q_{\text {in }}(t)+V(t-1)\right.$, month $)$

\subsection{Model calibration and validation}

The statistical models were calibrated and validated over 168 months of available data for the baseline period, representing a total of 14 years from 1999 to 2004 and from 2009 to 2017. Moreover, a forward time-window approach was applied as a cross-validation technique to better estimate model fitting (i.e. based on training data) and predictive performance (i.e. based on temporally independent test data) using root mean square error (RMSE). The applied methodology is based on multiple separations of training and testing data sets. Within the first repetition, the predefined model setups (i.e. dam reservoir volumes and turbined outflows models) are calibrated using a subset of the original data that relates to the first 110 months of available data. The derived relationships are then tested using both training data (i.e. fitting performance) and the data set that relates to the remaining (not yet) considered months (i.e. predictive performance). The following 58 repetitions are based on the same procedure, but on increasingly larger training data sets (i.e. consecutively adding 1 month within the forward time-window approach). This methodology allows to overcome some limitations of common one-fold non-temporal validation methods (splitting of training and test data randomly; e.g. hold-out validation) associated with data temporal dependencies (i.e. autocorrelation) and an arbitrary choice of training and validation subsets. Furthermore, the applied procedure allows a more robust estimation of model performance and its variability using multiple temporally independent subsets of the original data (Hastie, 2009; Varma and Simon, 2006; Tashman, 2000; Kohavi, 1995). A major advantage of such multi-fold partitioning strategies is the possibility to exploit all the available data for the generation of the final prediction model. 


\subsection{Future projections}

Future water inflow to the reservoir (coming from the GeoTransf application) were used to simulate future volumes stored in the S.Giustina reservoir. GeoTransf simulations considered unchanged maximum water withdrawals in the Noce catchment in the future and integrated downscaled COSMO-CLM climate scenarios (Bellin et al., 2016; Bucchignani et al., 2016). Such climate projections have been demonstrated to well represent climate forcing variables (i.e. precipitation and temperature) over Alpine regions (Montesarchio et al., 2013).

The RCP4.5 and 8.5 scenarios were selected according to the IPCC AR5 (IPCC, 2014a). Simulations stretched over two 240 30-year time horizons to represent short-term (2021-2050) and long-term (2041-2070) future climate conditions, affecting the Noce river flow, and the S.Giustina dam reservoir and its management.

Moreover, this study considered the number of times volume projections in the future exceed the $30^{\text {th }}$ and $80^{\text {th }}$ quantile thresholds corresponding to low and high levels of volume stored respectively. Such thresholds were calculated from the baseline data and were already identified in previous studies as significant levels to assess critical states in reservoirs (Majone 245 et al., 2016; Yilmaz et al., 2008).

A Monte Carlo approach was implemented by randomly sampling from the simulated future water volume predictions and replicating possible reservoir critical state conditions more than 10000 times for each future climate scenario. In particular, the Monte Carlo approach considered a moving sampling set having a time-window of 14 years across the simulated 30 years of future water volume predictions per scenario to compare it with the available 14 years from the baseline.

\section{Results}

\subsection{Baseline period}

The linear mixed-effect model was used to replicate observations of water volumes stored in the S.Giustina reservoir (Figure 4). The model gave an $R^{2}=0.68$, and mean RMSE of $12.12 \mathrm{Mm}^{3}$. Figure 4 shows the modelled and real values, with volume ranging from 0 (i.e. no usable volume) and a maximum level of $151.20 \mathrm{Mm}^{3}$, or up to $159.30 \mathrm{Mm}^{3}$ in case of flood prevention. Simulated volume values greater than the maximum allowed for flood were limited to such a maximum value. 


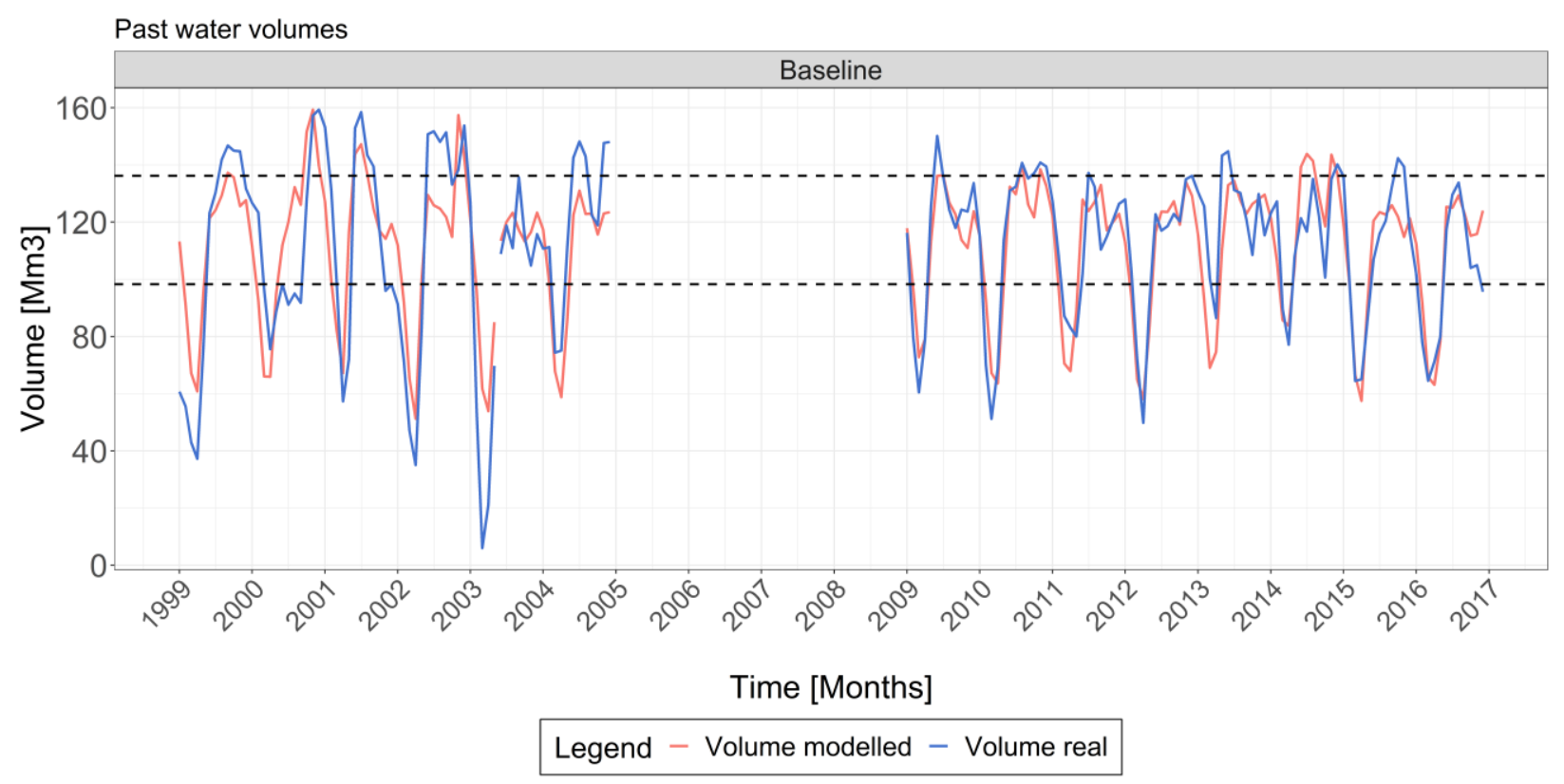

Figure 4 - S.Giustina time-series of water volume. Measured (blue line) and modelled (red line) water stored in S.Giustina from 1999 to 2017. Adjusted-R2 $=0.68$, mean $\mathrm{RMSE}=12.12 \cdot \mathrm{Mm} 3$

The same procedure was undertaken for simulating water turbined outflows (Figure 5). The maximum discharge of water flow to the turbines is $176 \mathrm{Mm}^{3} \cdot \mathrm{month}^{-1}$ for 31 days of full turbine operations. Equation 2 was applied to estimate the water turbined outflows used for hydropower production resulting in a $R^{2}=0.74$, and mean RMSE of $12.35 \mathrm{Mm}^{3} \cdot \mathrm{month}^{-1}$. In both cases, the water inflowing to the S.Giustina reservoir, and modelled using the GeoTransf hydrological model, played a key role influencing the water stored and hence the water turbined outflows. This influence of the inflow variable on both volume and turbined outflows is likely due to the low values of reservoir volume compared to the monthly inflow values, which was identified as the most important predictor (further information on model tests and performances are reported in the Supplementary material). 


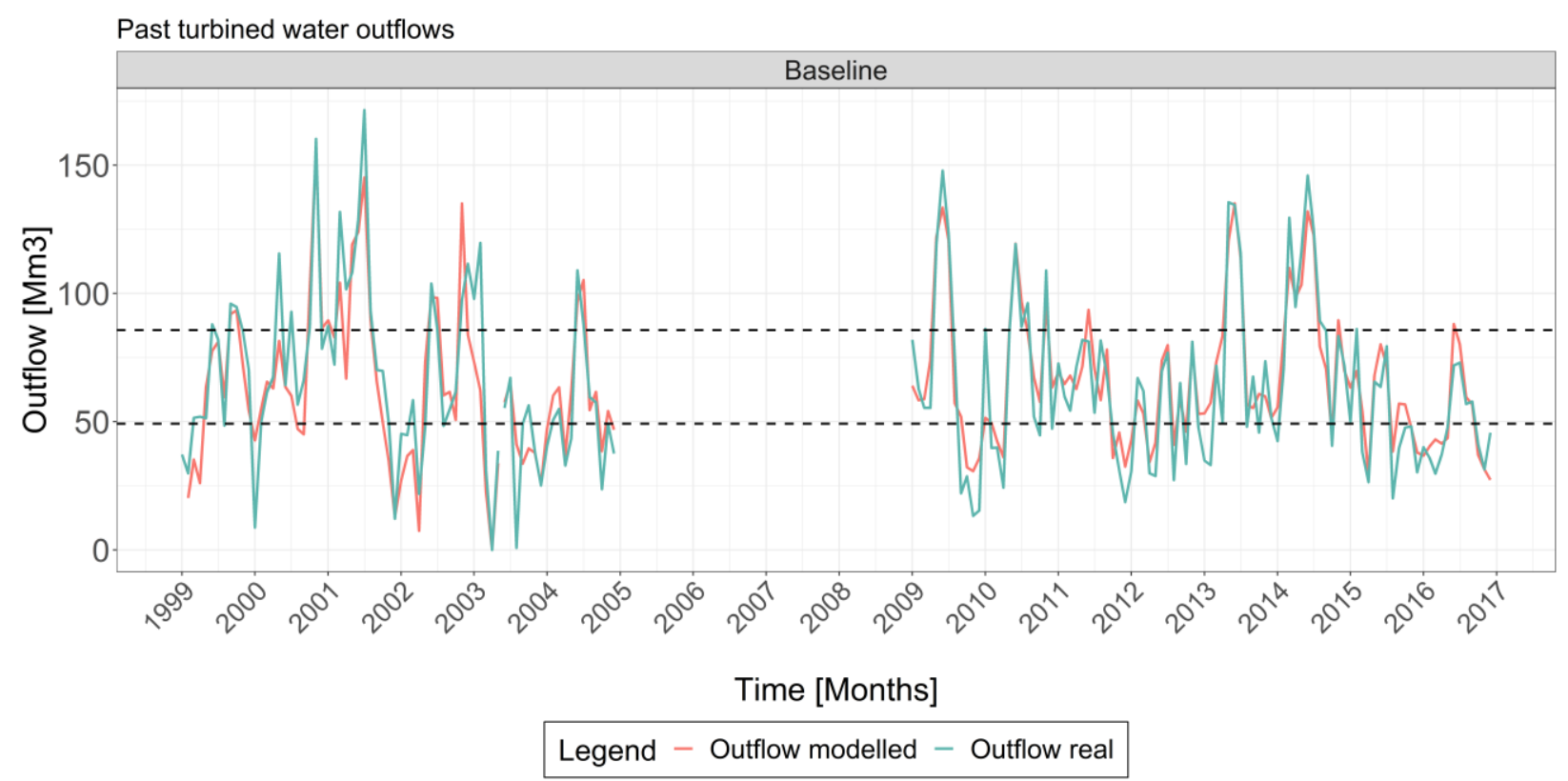

Figure 5 - S.Giustina time-series of water diverted to the turbines. Measured (blue line) and modelled (red line) water outflowing from the S.Giustina reservoir from 1999 to 2017. Adjusted-R2= $0.74, \mathrm{RMSE}=12.35 \mathrm{Mm} 3$

\subsection{Future projections}

Future GeoTransf model results forced by the COSMO-CLM climate projections depict a situation of general decreases in precipitation and water inflowing to the reservoir (Table 3 and Figure 6). However, such decreases differ for the two climate change scenarios. The short-term RCP4.5 scenario shows a substantial decrease of precipitation compared to the baseline while RCP8.5 projects a slight increase of precipitation until 2050. However, such little increase seems to have no substantial consequences on the water flowing into the reservoir and consequently on the volume of water stored.

Table 3 - Annual average values of temperature and precipitation (COSMO-CLM projections), water inflow to the S.Giustina reservoir, volume stored and water turbined (simulations), and their percentage differences compared to baseline values. $* B a s e l i n e$ period for climate data goes from 1975 to 2005 , while for water inflow and volume stored spans over 14 years from 1999 to 2004 and from 2008 to 2017.

\begin{tabular}{lc|cccc|cccc}
\hline & Baseline & \multicolumn{4}{c|}{ RCP4.5 } & \multicolumn{4}{c}{ RCP8.5 } \\
\hline \multirow{2}{*}{ Variable } & $*$ & \multicolumn{2}{|c|}{$\mathbf{2 0 2 1 - 2 0 5 0}$} & $\mathbf{2 0 4 1 - 2 0 7 0}$ & \multicolumn{2}{c}{$\mathbf{2 0 2 1 - 2 0 5 0}$} & $\mathbf{2 0 4 1 - 2 0 7 0}$ \\
\cline { 2 - 10 } & Value & Value & $\Delta[\%]$ & Value & $\Delta[\%]$ & Value & $\Delta[\%]$ & Value & $\Delta[\%]$ \\
\hline Temperature $\left[{ }^{\circ} \mathrm{C}\right]$ & 5.06 & 6.46 & +0.5 & 7.5 & +0.9 & 6.63 & +0.5 & 8.1 & +1.1 \\
\hline $\begin{array}{l}\text { Precipitation } \\
{[\text { mm/year }]}\end{array}$ & 1495.1 & 1433.55 & -4.1 & 1391.5 & -6.9 & 1516.3 & +1.5 & 1430.7 & -4.3 \\
\hline $\begin{array}{l}\text { Inflow } \\
{[\text { Mm3/month] }}\end{array}$ & 71.38 & 57.35 & -19.65 & 58.25 & -18.40 & 65.90 & -7.67 & 56.28 & -21.15 \\
\hline $\begin{array}{l}\text { Outflow } \\
{[\text { Mm3/month] }}\end{array}$ & 65.04 & 52.33 & -19.54 & 53.18 & -18.23 & 59.95 & -7.82 & 51.54 & -20.76 \\
\hline Volume $[\mathrm{Mm} 3]$ & 111.02 & 106.10 & -4.43 & 106.46 & -4.11 & 109.15 & -1.69 & 105.81 & -4.70 \\
\hline
\end{tabular}


https://doi.org/10.5194/nhess-2021-114

Preprint. Discussion started: 21 April 2021

(c) Author(s) 2021. CC BY 4.0 License.
Natural Hazards and Earth System Sciences

Discussions

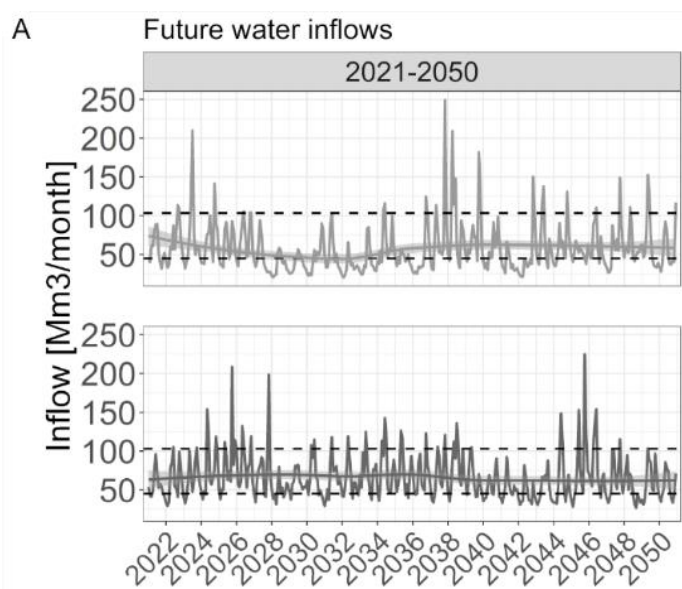

B

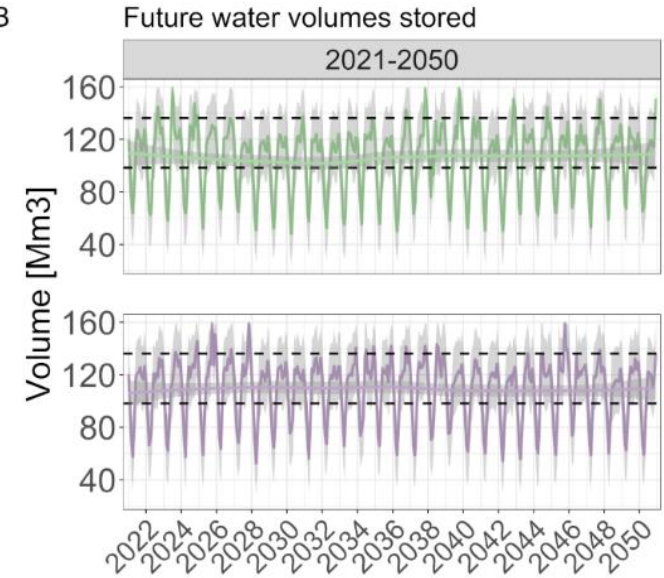

C

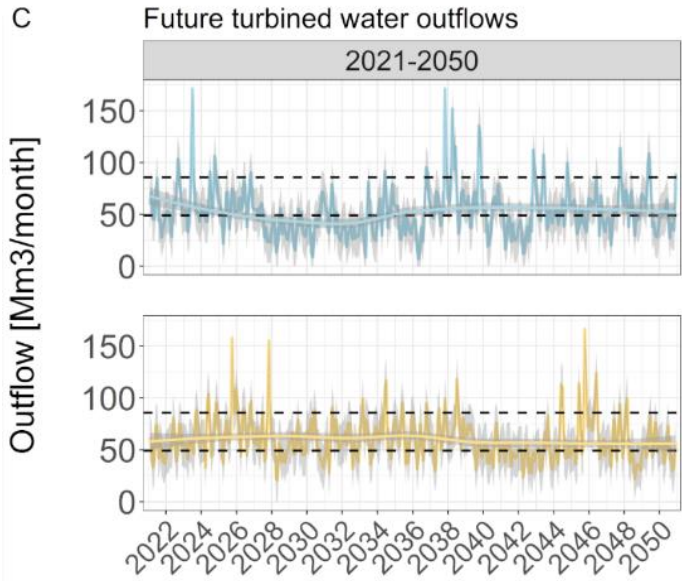

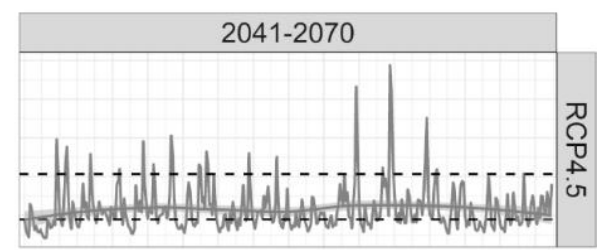
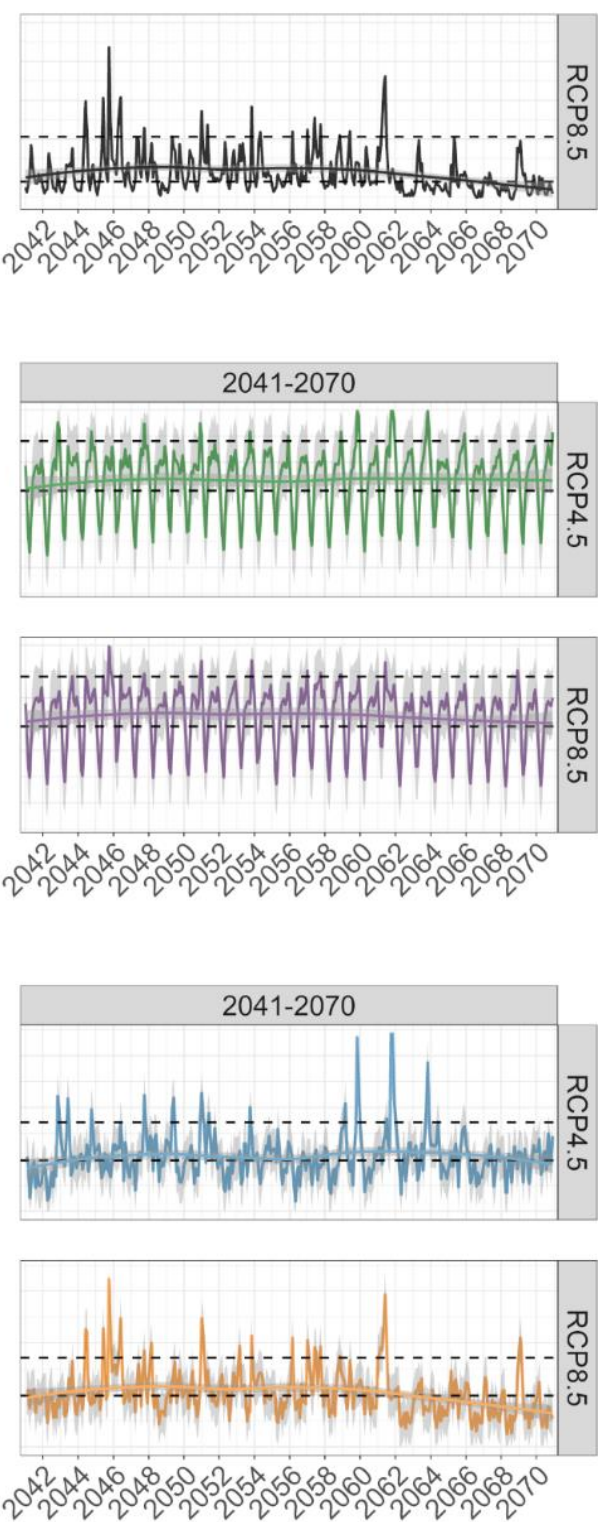

Time [Months]

Figure 6 - Plots with future projections for: A simulated water inflow to the S.Giustina reservoir, B simulated water turbined and $\mathrm{C}$ simulated future water volume stored in the S.Giustina reservoir. Dotted lines indicate baseline 30th and 80th quantiles. Grey shaded represents the confidence interval for the simulated outflows and water volumes. 
Considering average values over 30-year simulations, RCP4.5 results show a greater percentage reduction of inflow, outflow and volume $(-19.65,-19.54$ and $-4.43 \%$ respectively) in the short-term compared to the long-term future, where reductions are similar, but slightly lower $(-18.40,-18.23$ and $-4.11 \%)$. Future conditions under RCP8.5 show greater differences between short- and long-term future. Inflow, outflow and volume reductions are lower for the short-term future ($7.67,-7.53,-1.69 \%)$ and are associated with the only case of precipitation increase $(+1.5 \%)$. While in the long-term results show the greatest increase of temperature $(+1.1 \%)$, reduction of precipitation $(-4.3 \%)$ as well as for inflow, outflow and volume $(-21.15,-20.76,-4.70 \%)$.

Results at monthly temporal scale are reported in Figure 7 and averaged for each month over the 30-year simulation and compared to the baseline (i.e. percentage change; Figure 7). All climate scenarios agree on the general volume decrease in spring and summer down to a minimum of $-16.1 \%$ for the RCP4.5 short-term case. Scenarios also agree on the negative trend in November where RCP8.5 in the long-term scenario reaches the lowest minimum of $-6.5 \%$ of volume difference. However, scenarios disagree in terms of volume for January, February, March and October.

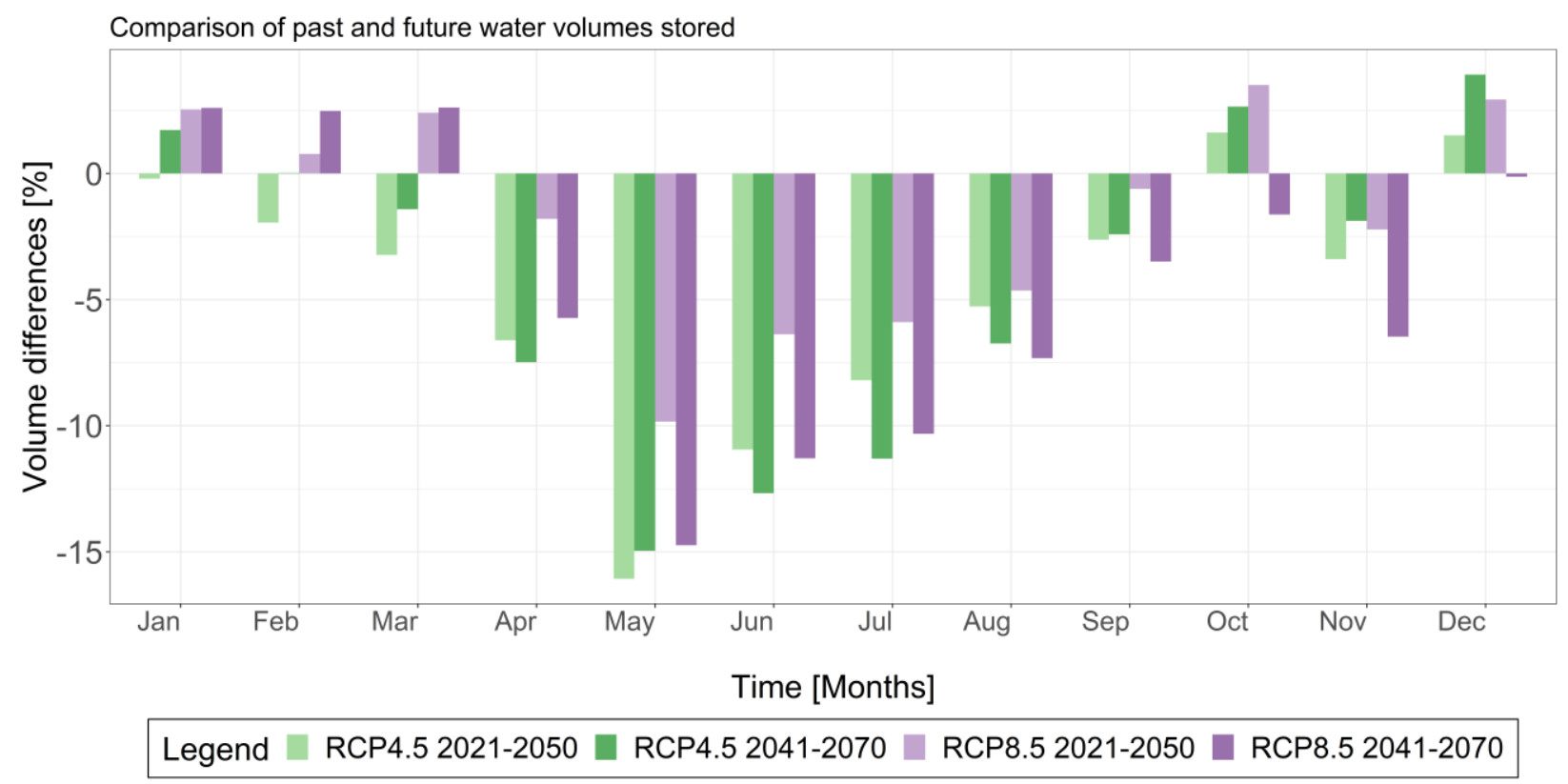

Figure 7 - Percentage change of volume [\%] comparing the 4 climate scenarios to the baseline at monthly level

Such disagreement provides important information on the timing of potential reservoir management adaptation, while the small volume increases are insufficient to counterbalance spring and summer reductions. In particular, short-term RCP4.5 depicts conditions of continuous negative volume trends througout the year, which are associated with lower precipitation values compared with RCP8.5 in northern Italy (Bucchignani et al., 2016). Nevertheless, positive volume increases, albeit minor, are expected during October and December $(+1.6$ and $+1.5 \%)$. Long-term RCP4.5 shows volume increases for January, February, October and December $(+1.7,+0.02,+2.7 \%$ and $+3.9 \%)$. Short-term RCP8.5 shows the most favourable conditions of water volumes, depicting positive differences in January $(+2.5 \%)$, February $(+0.8 \%)$, March $(+2.4)$, October $(+3.5 \%)$, and 
December $(+2.9 \%)$. While the long-term RCP8.5 envisages the first three months of the year having positive values $(+2.6 \%$, $+2.5 \%,+2.6 \%$ ) and the rest of the year with negative values down to $-14.7 \%$ in May.

Moreover, potentially critical states of stored reservoir water volumes (both high and low) were explored to further understand how climate change may impact on long-term reservoir operations and its vulnerability. The number of events lower than the $30^{\text {th }}$ and greater than the $80^{\text {th }}$ quantiles of stored volume were calculated on future predictions considering a moving time-window of 14 years and comparing to the 14 years of the baseline (Figure 8). Boxplots of the $30^{\text {th }}$ quantile threshold show an increasing number of low-volume events for RCP4.5 with a median of 64 events for the short-term and 57 for the long-term $(+33.3 \%$ and $+18.8 \%$ respectively compared to the baseline). RCP8.5 shows an increase similar to that for the long-term RCP4.5, with a larger interquantile range towards lower values. Increased values are depicted for the long-term RCP8.5 with a median of 52 events $(+8.3 \%)$ though lower compared to the other scenarios and having a wider interquantile range towards more low volume events.

Conditions for events greater than the $80^{\text {th }}$ quantile show a decrease in the number of high volume events for RCP4.5 both short- and long-term (both with a median of 24 events) compared to the 32 events of the baseline. Consistent with previous considerations, RCP4.5 predicts a decrease in the number of high volume events, confirming the trend of water stored reduction both in terms of minimum and maximum volumes (-4.43\% for the short-term and $-4.11 \%$ for the long-term values, Table 3 ). Moreover, RCP8.5 depicts a small increase in the number of high volume events (33 events, $+3.13 \%$ ) in the short-term scenario, but also showing a strong decrease in the long-term scenario reaching 23 events (-28.13\%).

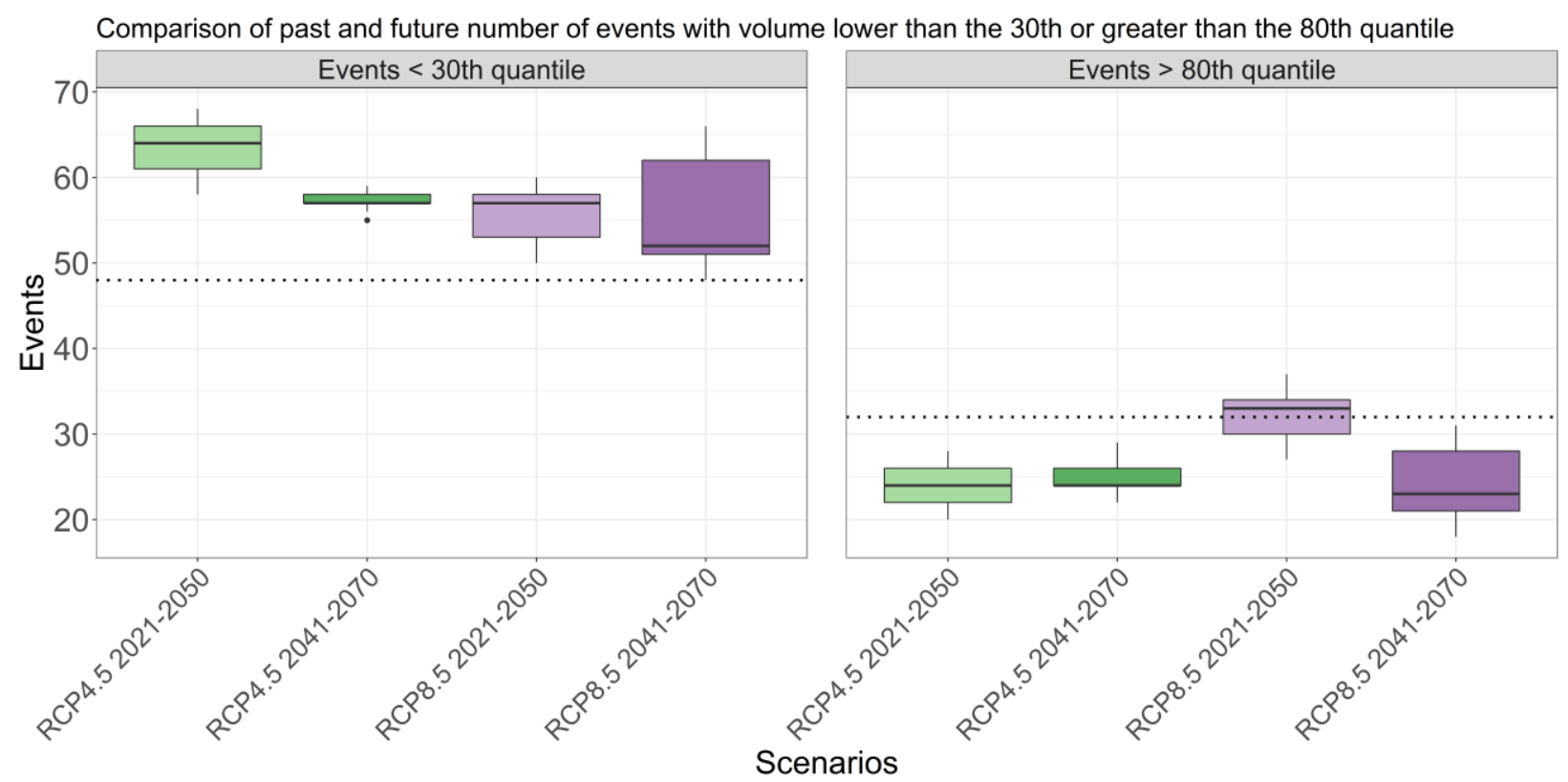

Figure 8 - Number of events lower than the 30th and greater than the 80th baseline quantile for future scenarios of water volume in the S.Giustina reservoir using a Monte Carlo approach. The dotted line shows the number of events for the baseline 
Future conditions of turbined water outflows considered a monthly average over the whole simulation period compared to the baseline (Figure 9). Highest reductions are reported for spring and summer with differences up to $-44.7 \%$ for the RCP4.5 short-term scenario. All scenarios agree on a water flow reduction during November reaching a minimum of $-28.8 \%$ of turbined outflow for RCP8.5 long-term scenario. In all other months, scenarios depict varying conditions of water flow. In particular, short-term RCP4.5 depicts conditions of negative differences for almost every month of the year except for October $(+6.2 \%)$ and December $(+4.2 \%)$. Increased number of positive differences are predicted for long-term RCP4.5 during January $(+11.1 \%)$, February $(+2.7 \%)$, October $(+12.5 \%)$ and December $(+19.3 \%)$. Short-term RCP8.5 shows larger positive differences during January $(+10.4 \%)$, February $(+4.9 \%)$, March $(+5.5 \%)$ and October $(+20.2 \%)$. Long-term RCP8.5 projects a negative trend for most of the year reaching persisting negative conditions in summer down to $-44.5 \%$ for August, overlapping with the summer electricity peak loads and calling for particular attention (Terna, 2019). Nevertheless, positive values are expected for January $(+9.3 \%)$, February $(+10.9 \%)$ and March $(+9.3 \%)$, when the winter electricity peak load usually occurs (Terna, 2019).

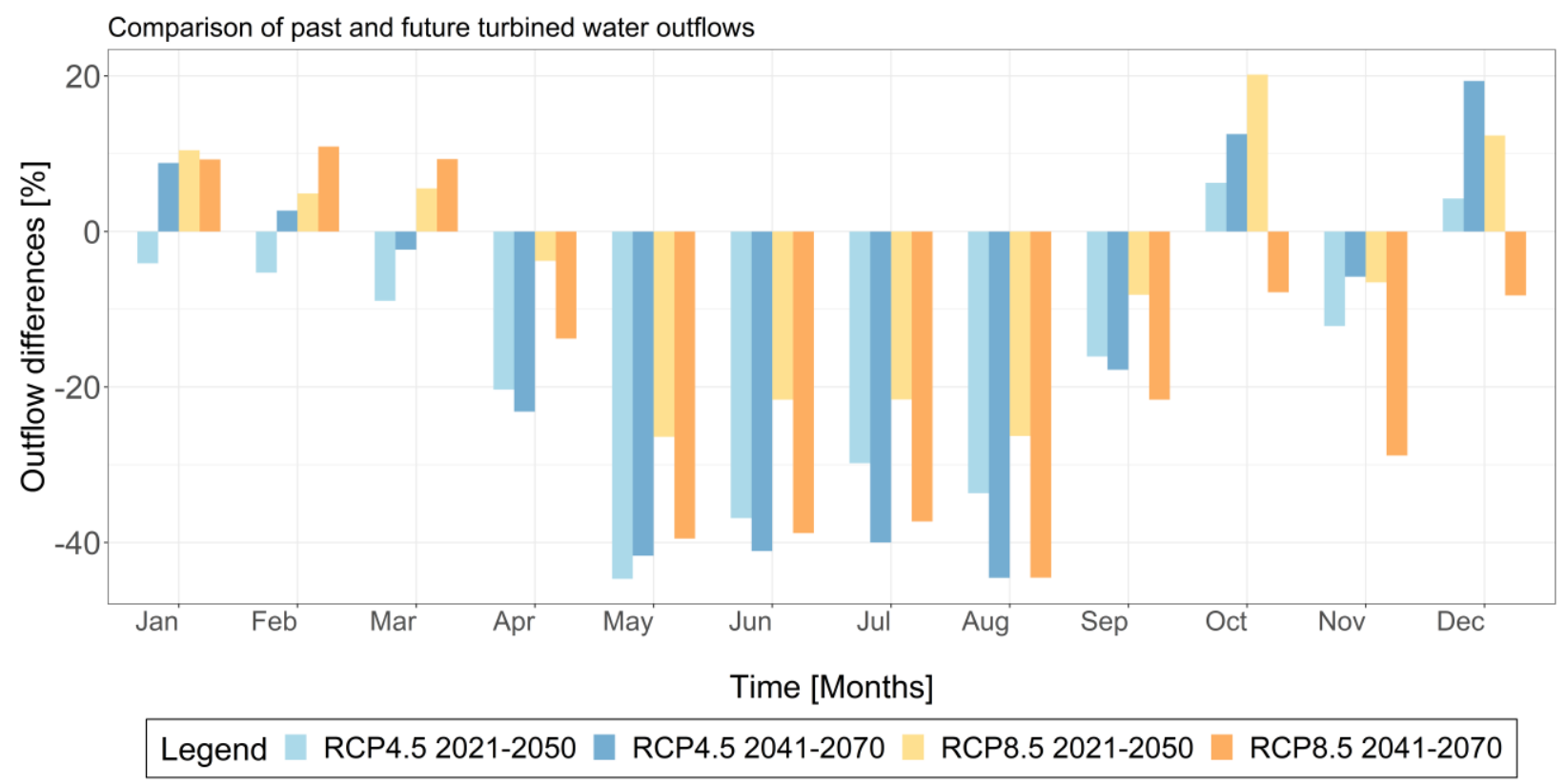

Figure 9 - Percentage change of turbined water outflows [\%] comparing the 4 climate scenarios to the baseline at monthly level

\section{Discussion}

Results show how the amount of water flowing into the reservoir is expected to negatively change with severe consequences even under the RCP4.5 scenario. Results during months of highest reduction of volume and turbined water outflows (i.e. from April to September) provide useful information on possible consequences coming from reservoir operations and climate change effects (i.e. $-4.43 \%$ of volume, $+33.3 \%$ in the number of events with low stored volume, $-4.43 \%$ in the number of high-volume events and $-19.54 \%$ of turbined water outflow). The SDM represents the overall trend of the system 
characterized by conditions of high-water demand for hydropower production and slow onset conditions of water availability variations over a 30-year period. Such conditions affect the actual water turbined and hence the hydropower production, which plays a strategic role in the economy of the province, as in the whole Alpine region. Moreover, reduction in the water streamflow can have consequences in terms of ecological hazards and water supply quality downstream of the reservoir.

Considering those months of positive variations of volume and turbined water outflows (i.e. autumn and winter months, November excluded) provides insights on the need to plan adaptation and operational strategies to improve the management of the S.Giustina reservoir according to the timing of positive water volume changes aiming to prepare for more frequent negative volume variations in spring and summer. These results are in line with other findings in the Alps showing the need for earlier reservoir water accumulation during winter to prevent downstream conditions of water shortages during summer (Brunner et al., 2019; Hendrickx and Sauquet, 2013).

Such negative variations are supported by the increasing number of future water scarcity conditions of high and low volumes stored, especially in a long-term perspective. At the same time, high volume events decrease in number, confirming previous results of a general negative trend of water stored. Results on the increase in the number of low-volume states are in agreement with the predictions reported in Majone et al., (2016) on future reductions of medium and low flows. Moreover, Monte Carlo results (Figure 8) provide additional information on the substantial reduction of high volume values for S.Giustina for long-term climate scenarios.

In general, the results suggest exacerbated risks to reservoir operation with acute water reductions in spring and summer, but also chronic reductions lasting throughout autumn and part of winter, threatening water supply security, hydropower production, and ecosystem services in the valley. Results should be considered in future plans to change S.Giustina management practices to reduce climate change impacts on reservoir operations. The findings presented reinforce the Alpine 'water tower' region's vulnerability to supply water and ensure its use for power production.

\subsection{Limitations of the study}

The applied SDM is mainly considering outputs from the GeoTransf applications integrating the COSMO-CLM climate projections. However, several assumptions and limitation in this study are noted.

Accounting for the GeoTransf application means relying on a very accurate water evaluation within the catchment, but also considering one climate model (i.e. COSMO-CLM) for future projections. This model has been demonstrated to well represent conditions in mountain regions (Montesarchio et al., 2013) and differently from other climate models depicts general conditions of decreased precipitation over the catchment (Table 3). Hence it provides conservative information on possible impacts on streamflow and volume management. The results from the GeoTransf application assumed a conservative condition of upstream water use set at the maximum licensed withdrawals values. This information was kept unchanged for future scenarios, although possible variations in the future (e.g. from agricultural and touristic uses) may affect river water flows. Moreover, the presented study considered precipitation, water flow and volume trends over a 30-year period, focusing on longterm variations, but potentially missing more intense (i.e. short duration) precipitation episodes. 
As reported in section 3.4, the available data on the reservoir volume was limited, hence affecting the model predicting performance. To compensate for these limitations, more advanced validation techniques were investigated and employed (i.e. forward time-window approach), contributing to a better understanding of the model error and performance.

The statistical models are a quick and effective tool to replicate past observations of water volume and turbined water outflows. Applying such a regression to future conditions of predictors, reservoir management was assumed to be stationary over time. Nevertheless, such a constraint is justified by the high uncertainty associated to future changes in hydropower production patterns affected by societal conditions (e.g. energy price fluctuations) (Gaudard et al., 2014; Ranzani et al., 2018). Moreover, the selected models considered only a few variables. Although other variables play important roles within the management of the reservoir at different temporal resolution (e.g. hourly energy market price), the monthly simulation step allowed to represent variation over a long term perspective.

\section{Conclusions}

The S.Giustina reservoir plays a crucial role in buffering water variations in the Noce catchment and downstream. Due to its size, type and position it is strategic for hydropower regulation and hydrologically disconnecting upstream with downstream river flow.

The combination of outputs from climate change and hydrological models with a stochastic SDM proved to be a quick and effective tool to explore the S.Giustina reservoir volume and turbined outflows looking at their critical conditions.

In particular, results of acute reductions on water stored and turbined outflows in spring and summer call for adaptation strategies of earlier reservoir water accumulation during autumn and winter, months of expected increases in water availability. Such a strategy could prevent downstream conditions of water shortages during summer, while also preparing for reductions in hydroelectric production especially during summer months of high electricity peak loads. Adaptation strategies should consider the chronic effects of volume and outflow reductions during autumn and winter, causing long periods of negative variations and hence calling for reductions in electricity and downstream water demands (e.g. for agricultural and domestic uses).

Future model expansions include water demand from multiple human activities (e.g. agriculture and domestic) and their effects on water availability reduction from upstream to downstream. By doing so, SDM models can support the understanding of criticalities connected to unsustainable water demands and anticipate critical conditions, to inform dam managers and local authorities on the timing and importance of climate change adaptation strategies. Moreover, the use of open codes and libraries for the assessment of variables interactions through statistical models make SDM transferrable to other cases at interregional / transnational scale in combination with available water flows datasets and open hydrological models (e.g. Copernicus, LISFLOOD model).

Finally, this analysis sheds light on the need to consider future changes in water availability and their consequences on already existing human activities relying on abundance water resources, and hence unprepared to quickly adapt to future 
410 climate impacts. This is the first step for more comprehensive water scarcity assessments in order to provide policy-makers with information on potential adaptation strategies to gain systemic leverage effects in line with the European Water Framework Directive on sustainable water management and climate change adaptation in the Alps (Alpine convention, 2013; European Commission, 2018, 2021).

\section{Code availability}

415 The source code for data processing and analysis developed in this study is freely available at https://github.com/Sterzi/SGiustina future SDM.

\section{Author contribution}

Stefano Terzi: conceptualization, data curation, formal analysis, methodology, software, validation, visualization, writing original draft preparation. Janez Susnik: conceptualization, formal analysis, methodology, writing - review \& editing; Stefan

420 Schneiderbauer: visualization, supervision, writing - review \& editing; Silvia Torresan: visualization, supervision, writing - review \& editing, Andrea Critto: supervision, writing - review \& editing.

\section{Competing interests}

The authors declare that they have no conflict of interest.

\section{Acknowledgements}

425 The authors acknowledge Eurac Research for supporting the research activities on multi-risk assessment in mountain regions within the context of climate change and the Provincia autonoma di Bolzano-Alto Adige - Ripartizione Innovazione, Ricerca e Università as financing institution of the AquaMount project. The authors also thank the Autonomous Province of Trento for data provision and Oscar Cainelli for making available data and hydrological model output.

\section{References}

430 Alpine convention: Guidelines for Climate Change Adaptation at the local level in the Alps, 2013.

Di Baldassarre, G., Viglione, A., Carr, G., Kuil, L., Yan, K., Brandimarte, L. and Blöschl, G.: Debates - Perspectives on sociohydrology: Capturing feedbacks between physical and social processes, Water Resour. Res., 51(6), 4770-4781, doi:10.1002/2014WR016416, 2015.

Barnett, T. P., Adam, J. C. and Lettenmaier, D. P.: Potential impacts of a warming climate on water availability in snow- 
dominated regions, Nature, 438(7066), 303-309, doi:10.1038/nature04141, 2005.

Bates, D., Mächler, M., Bolker, B. M. and Walker, S. C.: Fitting linear mixed-effects models using lme4, J. Stat. Softw., 67(1), doi:10.18637/jss.v067.i01, 2015.

Bellin, A., Majone, B., Cainelli, O., Alberici, D. and Villa, F.: A continuous coupled hydrological and water resources management model, Environ. Model. Softw., 75, 176-192, doi:10.1016/j.envsoft.2015.10.013, 2016.

440 Beniston, M. and Stoffel, M.: Assessing the impacts of climatic change on mountain water resources, Sci. Total Environ., 493, 1129-1137, doi:10.1016/j.scitotenv.2013.11.122, 2014.

Brunner, M. I., Björnsen Gurung, A., Zappa, M., Zekollari, H., Farinotti, D. and Stähli, M.: Present and future water scarcity in Switzerland: Potential for alleviation through reservoirs and lakes, Sci. Total Environ., 666, 1033-1047, doi:10.1016/j.scitotenv.2019.02.169, 2019.

445 Bucchignani, E., Montesarchio, M., Zollo, A. L. and Mercogliano, P.: High-resolution climate simulations with COSMOCLM over Italy: Performance evaluation and climate projections for the 21st century, Int. J. Climatol., 36(2), 735-756, doi:10.1002/joc.4379, 2016.

Chiogna, G., Skrobanek, P., Narany, T. S., Ludwig, R. and Stumpp, C.: Effects of the 2017 drought on isotopic and geochemical gradients in the Adige catchment, Italy, Sci. Total Environ., 645, 924-936, doi:10.1016/j.scitotenv.2018.07.176, 4502018.

Convention, A.: Report on the State of the Alps Alpine Signals - Special Edition 2, Water water Manag. issues, 2, $235,2009$.

Davies, E. and Simonovic, S. P.: Global water resources modeling with an integrated model of the social-economicenvironmental system, Adv. Water Resour., 34(6), 684-700, doi:10.1016/j.advwatres.2011.02.010, 2011.

Davies, E. G. R. and Simonovic, S. P.: An Integrated System Dynamics Model for Analyzing Behaviour of the Social455 Economic-Climatic System: Model Description and Model Use Guide, Department of Civil and Environmental Engineering, The University of Western Ontari., 2008.

Duggan, J.: System Dynamics Modeling with R, Springer International Publishing, Switzerland., 2016.

Duran-Encalada, J. A., Paucar-Caceres, A., Bandala, E. R. and Wright, G. H.: The impact of global climate change on water quantity and quality: A system dynamics approach to the US-Mexican transborder region, Eur. J. Oper. Res., 256(2), 567-581, 460 doi:10.1016/j.ejor.2016.06.016, 2017.

Etter, S., Addor, N., Huss, M. and Finger, D.: Climate change impacts on future snow, ice and rain runoff in a Swiss mountain catchment using multi-dataset calibration, J. Hydrol. Reg. Stud., 13(February), 222-239, doi:10.1016/j.ejrh.2017.08.005, 2017.

European Commission: Commission Staff working document Evaluation of the EU Strategy on adaptation to climate change

465 Accompanying- Accompanying the document Report from the Commission to the European Parliament and the Council on the implementation of the EU Strategy on adapt, SWD(2018) 460 Final, 1-65, 2018.

European Commission: Forging a climate-resilient Europe - the new EU Strategy on Adaptation to Climate Change., 2021.

European Parliament \& Council: DIRECTIVE 2000/60/EC, Anal. Proc., 21(6), 196, doi:10.1039/AP9842100196, 2000. 
https://doi.org/10.5194/nhess-2021-114

Preprint. Discussion started: 21 April 2021

(c) Author(s) 2021. CC BY 4.0 License.

Farinotti, D., Usselmann, S., Huss, M., Bauder, A. and Funk, M.: Runoff evolution in the Swiss Alps: Projections for selected

high-alpine catchments based on ENSEMBLES scenarios, Hydrol. Process., 26(13), 1909-1924, doi:10.1002/hyp.8276, 2012. Ford, A.: Modelling the Environment: An Introduction to System Dynamics Modeling of Environmental Systems (2nd Edition)., Isl. Press, 400, 2010.

Forests, R.: Random Forests 15.1, Elements, 27(2), 587-604, doi:10.1007/b94608, 2001.

Forrester, J. W.: World Dynamics, Wright-Allen Press., 1971.

475 Fuhrer, J., Smith, P. and Gobiet, A.: Implications of climate change scenarios for agriculture in alpine regions - A case study in the Swiss Rhone catchment, Sci. Total Environ., 493, 1232-1241, doi:10.1016/j.scitotenv.2013.06.038, 2014.

Gaudard, L., Romerio, F., Dalla Valle, F., Gorret, R., Maran, S., Ravazzani, G., Stoffel, M. and Volonterio, M.: Climate change impacts on hydropower in the Swiss and Italian Alps, Sci. Total Environ., 493, 1211-1221, doi:10.1016/j.scitotenv.2013.10.012, 2014.

480 Gohari, A., Mirchi, A. and Madani, K. D. E. of C. C. A. S. for W. R. M. in C. I.: System Dynamics Evaluation of Climate Change Adaptation Strategies for Water Resources Management in Central Iran, Water Resour. Manag., 31(5), 1413-1434, doi:10.1007/s11269-017-1575-z, 2017.

Hanel, M., Rakovec, O., Markonis, Y., Máca, P., Samaniego, L., Kyselý, J. and Kumar, R.: Revisiting the recent European droughts from a long-term perspective, Sci. Rep., 8(1), 1-11, doi:10.1038/s41598-018-27464-4, 2018.

485 Hendrickx, F. and Sauquet, E.: Impact du changement climatique sur la gestion de l'eau dans le bassin de l'Ariége, Hydrol. Sci. J., 58(5), 976-993, doi:10.1080/02626667.2013.788790, 2013.

van den Heuvel, L., Blicharska, M., Masia, S., Sušnik, J. and Teutschbein, C.: Ecosystem services in the Swedish waterenergy-food-land-climate nexus: Anthropogenic pressures and physical interactions, Ecosyst. Serv., 44(August 2019), doi:10.1016/j.ecoser.2020.101141, 2020.

490 Huss, M. and Hock, R.: Global-scale hydrological response to future glacier mass loss, Nat. Clim. Chang., 8(2), 135-140, doi:10.1038/s41558-017-0049-x, 2018.

IPCC: Climate Change 2014: Impacts, Adaptation, and Vulnerability. Part A: Global and Sectoral Aspects. Contribution of Working Group II to the Fifth Assessment Report of the Intergovernmental Panel on Climate Change., 2014a.

IPCC: Climate Change 2014 Synthesis Report Summary Chapter for Policymakers, Ipcc, 31, 495 doi:10.1017/CBO9781107415324, 2014b.

IPCC: Global Warming of $1.5^{\circ} \mathrm{C}$. An IPCC Special Report on the impacts of global warming of $1.5^{\circ} \mathrm{C}$ above pre-industrial levels and related global greenhouse gas emission pathways, in the context of strengthening the global response to the threat of climate change, 2018.

La Jeunesse, I., Cirelli, C., Aubin, D., Larrue, C., Sellami, H., Afifi, S., Bellin, A., Benabdallah, S., Bird, D. N., Deidda, R., 500 Dettori, M., Engin, G., Herrmann, F., Ludwig, R., Mabrouk, B., Majone, B., Paniconi, C. and Soddu, A.: Is climate change a threat for water uses in the Mediterranean region? Results from a survey at local scale, Sci. Total Environ., 543, 981-996, doi:10.1016/j.scitotenv.2015.04.062, 2016. 
https://doi.org/10.5194/nhess-2021-114

Preprint. Discussion started: 21 April 2021

(c) Author(s) 2021. CC BY 4.0 License.

Kohavi, R.: A Study of Cross-Validation and Bootstrap for Accuracy Estimation and Model Selection, Int. Jt. Conf. Artif. Intell., (0), 0-6, 1995.

Laaha, G., Gauster, T., Tallaksen, L. M., Vidal, J. P., Stahl, K., Prudhomme, C., Heudorfer, B., Vlnas, R., Ionita, M., Van Lanen, H. A. J., Adler, M. J., Caillouet, L., Delus, C., Fendekova, M., Gailliez, S., Hannaford, J., Kingston, D., Van Loon, A. F., Mediero, L., Osuch, M., Romanowicz, R., Sauquet, E., Stagge, J. H. and Wong, W. K.: The European 2015 drought from a hydrological perspective, Hydrol. Earth Syst. Sci., 21(6), 3001-3024, doi:10.5194/hess-21-3001-2017, 2017.

Majone, B., Villa, F., Deidda, R. and Bellin, A.: Impact of climate change and water use policies on hydropower potential in the south-eastern Alpine region, Sci. Total Environ., 543, 965-980, doi:10.1016/j.scitotenv.2015.05.009, 2016.

Malard, J. J., Inam, A., Hassanzadeh, E., Adamowski, J., Tuy, H. A. and Melgar-Quiñonez, H.: Development of a software tool for rapid, reproducible, and stakeholder-friendly dynamic coupling of system dynamics and physically-based models, Environ. Model. Softw., 96(October 2017), 410-420, doi:10.1016/j.envsoft.2017.06.053, 2017.

Masia, S., Sušnik, J., Marras, S., Mereu, S., Spano, D. and Trabucco, A.: Assessment of Irrigated Agriculture Vulnerability under Climate Change in Southern Italy, Water, 10(2), 209, doi:10.3390/w10020209, 2018.

Meadows, D. H., Meadows, D. L., Randers, J. and Behrens, W. W.: The limits to growth, Universe Books, New York., 2018. Mehran, A., AghaKouchak, A., Nakhjiri, N., Stewardson, M. J., Peel, M. C., Phillips, T. J., Wada, Y. and Ravalico, J. K.: Compounding Impacts of Human-Induced Water Stress and Climate Change on Water Availability, Sci. Rep., 7(1), 1-9, doi:10.1038/s41598-017-06765-0, 2017.

Menk, L., Neuwirth, C. and Kienberger, S.: Mapping the Structure of Social Vulnerability Systems for Malaria in East Africa, Sustainability, 12(12), 5112, doi:10.3390/su12125112, 2020.

Mereu, S., Sušnik, J., Trabucco, A., Daccache, A., Vamvakeridou-Lyroudia, L., Renoldi, S., Virdis, A., Savić, D. and Assimacopoulos, D.: Operational resilience of reservoirs to climate change, agricultural demand, and tourism: A case study from Sardinia, Sci. Total Environ., 543, 1028-1038, doi:10.1016/j.scitotenv.2015.04.066, 2016.

Montesarchio, M., Manzi, M. P., Cattaneo, L. and Mercogliano, P.: Performance Evaluation of a Regional Simulation with COSMO-CLM in the Alpine Space, SSRN Electron. J., (July), doi:10.2139/ssrn.2195316, 2013.

Neuwirth, C., Hofer, B. and Peck, A.: Spatiotemporal processes and their implementation in Spatial System Dynamics models, J. Spat. Sci., 60(2), 277-288, doi:10.1080/14498596.2015.997316, 2015.

Pham, V., Sperotto, A., Torresan, S., Acua, V., Jorda-capdevila, D. and Rianna, G.: Coupling scenarios of climate and land use change with assessments of potential ecosystem services at the river basin scale, 2018.

Provincia Autonoma di Trento: PGUAP - Piano Generale di Utilizzazione delle Acque Pubbliche. Trento, 2006.

R Core Development Team: A language and environment for statistical computing., , 1, 2013.

Ranzani, A., Bonato, M., Patro, E. R., Gaudard, L. and De Michele, C.: Hydropower future: Between climate change, renewable deployment, carbon and fuel prices, Water (Switzerland), 10(9), 1-17, doi:10.3390/w10091197, 2018.

535 Rockel, B. and Geyer, B.: The performance of the regional climate model CLM in different climate regions, based on the example of precipitation, Meteorol. Zeitschrift, 17(4), 487-498, doi:10.1127/0941-2948/2008/0297, 2008. 
Ronco, P., Zennaro, F., Torresan, S., Critto, A., Santini, M., Trabucco, A., Zollo, A. L., Galluccio, G. and Marcomini, A.: A risk assessment framework for irrigated agriculture under climate change, Adv. Water Resour., 110, 562-578, doi:10.1016/j.advwatres.2017.08.003, 2017.

Rull, V.: Biodiversity, mountains and climate change., 2014.

Sahin, O. and Mohamed, S.: Coastal vulnerability to sea-level rise: A spatial-temporal assessment framework, Nat. Hazards, 70(1), 395-414, doi:10.1007/s11069-013-0818-4, 2014.

Simonovic, S. P.: Systems Approach to Management of Disasters, edited by Wiley., 2001.

Simonovic, S. P.: Systems approach to management of disasters: methods and applications, J. Integr. Disaster Risk Manag.,

545 5(2), 70-83, doi:10.5595/idrim.2015.0099, 2015.

Sivapalan, M., Savenije, H. H. G. and Blöschl, G.: Socio-hydrology: A new science of people and water, Hydrol. Process., 26(8), 1270-1276, doi:10.1002/hyp.8426, 2012.

Stave, K.: Participatory system dynamics modeling for sustainable environmental management: Observations from four cases, Sustainability, 2(9), 2762-2784, doi:10.3390/su2092762, 2010.

550 Stephan, R., Erfurt, M., Terzi, S., Žun, M., Kristan, B., Haslinger, K. and Stahl, K.: An Alpine Drought Impact Inventory to explore past droughts in a mountain region, , (March), 1-25, doi:10.5194/nhess-2021-24, 2021.

Sterman, J. D., Burr Ridge, B., Dubuque, I., Madison, I. and New York San Francisco St Louis Bangkok Bogota Caracas Lisbon London Madrid Mexico City Milan New Delhi Seoul Singapore Sydney Taipei Toronto, W.: Business Dynamics Systems Thinking and Modeling for a Complex World., 2000.

555 Sušnik, J., Vamvakeridou-Lyroudia, L. S., Savić, D. A. and Kapelan, Z.: Integrated modelling of a coupled water-agricultural system using system dynamics, J. Water Clim. Chang., 4(3), 209-231, doi:10.2166/wcc.2013.069, 2013.

Sušnik, J., Chew, C., Domingo, X., Mereu, S., Trabucco, A., Evans, B., Vamvakeridou-Lyroudia, L., Savić, D. A., Laspidou, C. and Brouwer, F.: Multi-stakeholder development of a serious game to explore the water-energy-food-land-climate nexus: The SIM4NEXUS approach, Water (Switzerland), 10(2), doi:10.3390/w10020139, 2018.

560 Tashman, L. J.: Out-of Sample Tests of Forecasting Accuracy: A Tutorial and Review, Int. J. Forecast., 16, 437-450, 2000. Terna: Dati generali, , 1-9 [online] Available from: https://download.terna.it/terna/1-DATI GENERALI_8d8e26126475683.pdf, 2019.

Terzi, S., Torresan, S., Schneiderbauer, S., Critto, A., Zebisch, M. and Marcomini, A.: Multi-risk assessment in mountain regions: A review of modelling approaches for climate change adaptation, J. Environ. Manage., 232(1), 759-771, doi:10.1016/j.jenvman.2018.11.100, 2019.

United Nations: The Future We Want: Outcome document of the United Nations Conference on Sustainable Development, 2012.

Varma, S. and Simon, R.: Bias in error estimation when using cross-validation for model selection, BMC Bioinformatics, 7 , 1-8, doi:10.1186/1471-2105-7-91, 2006.

570 Viviroli, D., Dürr, H. H., Messerli, B., Meybeck, M. and Weingartner, R.: Mountains of the world, water towers for humanity: 
https://doi.org/10.5194/nhess-2021-114

Preprint. Discussion started: 21 April 2021

(c) Author(s) 2021. CC BY 4.0 License.

(c) (i)

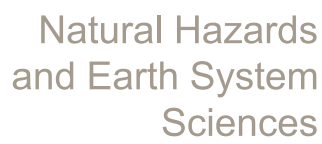

Discussions

Typology, mapping, and global significance, Water Resour. Res., 43(7), 1-13, doi:10.1029/2006WR005653, 2007.

Viviroli, D., Archer, D. R., Buytaert, W., Fowler, H. J., Greenwood, G. B., Hamlet, A. F., Huang, Y., Koboltschnig, G., Litaor, M. I., López-Moreno, J. I., Lorentz, S., Schädler, B., Schreier, H., Schwaiger, K., Vuille, M. and Woods, R.: Climate change and mountain water resources: Overview and recommendations for research, management and policy, Hydrol. Earth Syst. Sci., 575 15(2), 471-504, doi:10.5194/hess-15-471-2011, 2011.

Wever, N., Comola, F., Bavay, M. and Lehning, M.: Simulating the influence of snow surface processes on soil moisture dynamics and streamflow generation in an alpine catchment, Hydrol. Earth Syst. Sci., 21(8), 4053-4071, doi:10.5194/hess21-4053-2017, 2017.

Xu, D., Song, A., Tong, H., Ren, H., Hu, Y. and Shao, Q.: A spatial system dynamic model for regional desertification simulation - A case study of Ordos, China, Environ. Model. Softw., 83, 179-192, doi:10.1016/j.envsoft.2016.05.017, 2016.

Xu, J., Grumbine, R. E., Shrestha, A., Eriksson, M., Yang, X., Wang, Y. and Wilkes, A.: The melting Himalayas: Cascading effects of climate change on water, biodiversity, and livelihoods, Conserv. Biol., 23(3), 520-530, doi:10.1111/j.15231739.2009.01237.x, 2009.

Yilmaz, K. K., Gupta, H. V. and Wagener, T.: A process-based diagnostic approach to model evaluation: Application to the 585 NWS distributed hydrologic model, Water Resour. Res., 44(9), 1-18, doi:10.1029/2007WR006716, 2008.

Zebich, M., Vaccaro, R., Niedrist, G., Schneiderbauer, S., Streifeneder, T., Weiss, M., Troi, A., Renner, K., Pedoth, L., Baumgartner, B. and V, B.: Rapporto sul clima - Alto Adige 2018., 2018. 